\title{
Cloud processing of mineral dust: direct comparison of cloud residual and clear sky particles during AMMA aircraft campaign in summer 2006
}

\author{
A. Matsuki ${ }^{1,3}$, A. Schwarzenboeck ${ }^{1}$, H. Venzac ${ }^{1}$, P. Laj ${ }^{1}$, S. Crumeyrolle ${ }^{2}$, and L. Gomes ${ }^{2}$ \\ ${ }^{1}$ Laboratoire de Météorologie Physique, Université Blaise Pascal, Clermont-Ferrand, France \\ ${ }^{2}$ Centre National de Recherches Météorologiques, Météo-France, Toulouse, France \\ ${ }^{3}$ Frontier Science Organization, Kanazawa University, Japan
}

Received: 8 October 2008 - Published in Atmos. Chem. Phys. Discuss.: 20 January 2009

Revised: 22 December 2009 - Accepted: 7 January 2010 - Published: 1 February 2010

\begin{abstract}
In order to gain insights into the characteristics of the mineral dust particles incorporated in the actual cloud droplets and the related cloud processing, the French ATR42 research aircraft equipped both with a counterflow virtual impactor (CVI) and community aerosol inlet was deployed in Niamey, Niger $\left(13^{\circ} 30^{\prime} \mathrm{N}, 02^{\circ} 05^{\prime} \mathrm{E}\right)$ in August 2006 within the framework of the African Monsoon Multidisciplinary Analysis (AMMA) project.

Cloud residual and clear-sky particles were collected separately and analyzed individually using a transmission electron microscope (TEM) and a scanning electron microscope coupled with an energy dispersive X-ray spectroscopy (SEM-EDX). The analysis revealed interesting characteristics on the coarse dust particles $(D p>1 \mu \mathrm{m})$, particularly those which likely had acted as CCN.

Traces of heterogeneously formed secondary sulfate, chloride and nitrate were found on many dust particles (though fraction of sulfate may be present in the form of gypsum as primary dust component). These secondary species were particularly enhanced in clouds (i.e. cloud processing). The study illustrates that calcium-rich particles assumed to be carbonates (Calcite, Dolomite) contained the secondary species in significantly larger frequency and amount than the silicates (Quartz, Feldspar, Mica, Clay), suggesting that they represent the most reactive fraction of the mineral dust. A surprisingly large fraction of the Ca-rich particles were already found in deliquesced form even in clear-sky condi-
\end{abstract}

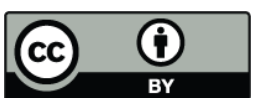

Correspondence to: A. Matsuki (matsuki@staff.kanazawa-u.ac.jp) tions, most probably reflecting their extreme hygroscopicity, resulting from their reaction with $\mathrm{HNO}_{3}$ gas.

Both silicate and Ca-rich particles were found dominant among the supermicron cloud residues, and they were supposed to be those previously activated as CCN. It is highly probable that the observed formation of soluble materials enhanced their cloud nucleating abilities.

\section{Introduction}

Mineral dust emitted into the atmosphere by the surfaces of the continental arid and semi-arid regions comprises an important fraction of the atmospheric aerosol. The Saharan desert with the Sahelian region is the largest global source (Tanaka et al., 2005). During the course of its aerial longrange transport, dust particles may influence the climate by interfering directly with the atmospheric radiative processes (Sokolik et al., 2001; Haywood et al., 2003) and indirectly by modifying the distribution of clouds (Lohmann et al., 2004).

The important role of dust particles acting effectively as ice nuclei (IN) has been rather well recognized (Isono et al., 1959; Heintzenberg et al., 1996; DeMott et al., 2003; Sassen et al., 2003; Twohy and Poellot, 2005). Dust particles may induce diverse indirect effects also through their interaction with warm clouds. On the one hand, they are suggested to serve as "giant CCN" which would facilitate the formation and growth of large cloud droplets into precipitating sizes (Levin et al., 1996; Feingold et al., 1999). On the other hand, dust particles are also claimed to suppress precipitation by causing the water competition among the increased number of CCN (Rosenfeld et al., 2001), known as cloud albedo and

Published by Copernicus Publications on behalf of the European Geosciences Union. 
cloud lifetime effects (Twomey, 1974; Albrecht, 1989). Determining the conditions for which dust particles enhance or suppress precipitation requires further measurements and understanding of their complex role as $\mathrm{CCN}$. The $\mathrm{CCN}$ activity of dust particles may depend highly on many environmental factors, such as the supersaturation and aerosol size distribution. Of particular concern is the influence of complex dust mineralogy and the following atmospheric processing, which will be the main focus of this study.

The mineral composition of individual dust particles is quite diverse already at the initial entrainment into the atmosphere. It is dependent on the soil type and the geological situation in the source regions, of which the soils derive. Although silicates are the largest component of the earth's crust, surface soils in some regions are reported to have significantly high contributions of carbonates and other evaporites (Ganor and Mamane, 1982; Okada and Kai, 1995; Formenti et al., 2003; Krueger et al., 2004; Kandler et al., 2007). The mineralogical maps of the surface erodible soils prepared by Claquin et al. (1999) illustrate global coverage of soils containing calcium carbonate.

The atmospheric processing of dust particles further complicates the issue. During transport in the troposphere, dust particles provide reaction surface for acidic gases such as $\mathrm{SO}_{2}$ to form sulfite, which is subsequently oxidized to sulfate, for example by gaseous ozone (Usher et al., 2002; Trochkine et al., 2003). Presence of nitrate can be found on the dust particles due to the heterogeneous reaction with $\mathrm{HNO}_{3}$ and other nitrogen oxides (Wu and Okada, 1994; Sullivan et al., 2007a). Mineral surface is also reported to act as a sink for the $\mathrm{HCl}$ gas liberated from sea salt particles (Zhang and Iwasaka, 2001; Ooki and Uematsu, 2005; Sullivan et al., 2007b). A result from these processes is the enhanced hygroscopicity of dust particles. In turn, such soluble coatings on aluminosilicate particles may have detrimental effect on their innate ice forming ability (Archuleta et al., 2005). Therefore, the cloud nucleating properties of dust particles at the initial point of their emission may be significantly altered after the long-range transport. The accumulation of secondary acids may have other climatic implications apart from potentially altering the ability of the dust particles serving as CCN or IN. For example, marine productivity in the remote oceans may be enhanced as a result of the increased iron solubility (Zhu et al., 1992).

Many of the previous works were based mainly on the analysis of aerosols under cloud-free conditions. They provided valuable information regarding the extent of dust modification in the atmosphere. However, it was often difficult to prove whether or not the observed modification involved any preceding cloud processing. Therefore, it is desirable to directly collect not only the cloud-free particles, but also particles incorporated in the actual droplets, and to compare their mixing states through individual particle analysis.

The airborne measurements were conducted in the framework of African Monsoon Multidisciplinary Analy- sis (AMMA) project. AMMA is an international project to improve our knowledge and understanding of the West African Monsoon (WAM) and its daily-interannual variabilities. Tropical Africa is one of the world's largest sources of atmospheric dust and biomass-burning aerosols. Both particles play a major role in radiative forcing and in cloud microphysics, and thus are an important part of the WAM system which requires further study. An overview of the project can be found elsewhere (Redelsperger et al., 2006).

\section{Aircraft measurement}

The frequent development of Mesoscale Convective Systems (MCS) and their easterly propagation are notably the main feature of the monsoonal season over the area studied during the AMMA project. However, it is not realistic to direct a manned aircraft into these highly convective systems. Instead, shallow stratocumulus clouds were studied under relatively calm conditions.

The French ATR-42 research aircraft was deployed near Niamey, Niger $\left(13^{\circ} 30^{\prime} \mathrm{N}, 02^{\circ} 05^{\prime} \mathrm{E}\right)$ in West Africa, during one of the special observation periods (SOP2a2: 219 August 2006) of AMMA project. The ATR-42 was equipped with two separate inlet probes, namely, the community aerosol inlet (CAI) and the counterflow virtual impactor (CVI).

The CAI is a forward facing aerosol inlet developed by Centre National de Recherches Météorologiques (CNRM, France), which is designed for the ATR to allow isokinetic and isoaxial sampling relative to the incoming air stream. Most recent calibration studies of the CAI inlet in the ECN chamber (Petten, Netherlands), proved that CAI collects particles smaller than $4 \mu \mathrm{m}$ (50\% collection efficiency) (L. Gomes, personal communication, 2009).

The CVI (Ogren et al., 1985) is designed to exclusively collecting cloud elements (cloud droplets and ice crystals), while rejecting interstitial aerosol particles. The subsequent evaportion of cloud elements in the particle free and dry return flow releases cloud residual particles. The counterflow of the CVI was constantly adjusted to maintain the diameter of the cloud elements to be $5 \mu \mathrm{m}$ ( $50 \%$ collection efficiency) or larger. Further details on the CVI can be found elsewhere (Schwarzenboeck and Heintzenberg, 2000; Schwarzenboeck et al., 2000). Thus, switching between the CVI in cloud and CAI in clear-sky conditions allowed direct sampling of either the cloud residual or total aerosol particles.

An optical particle counter (OPC, GRIMM, Portable Aerosol Spectrometer model 1.108) was monitoring the number concentration of larger particles entering the CAI and CVI probes. The OPC counts particles in the size range $0.3 \mu \mathrm{m}$ to $2 \mu \mathrm{m}$ in 8 size channels every second, with a volume flow rate of $1.2 \mathrm{~L} \mathrm{~min}^{-1}$. 


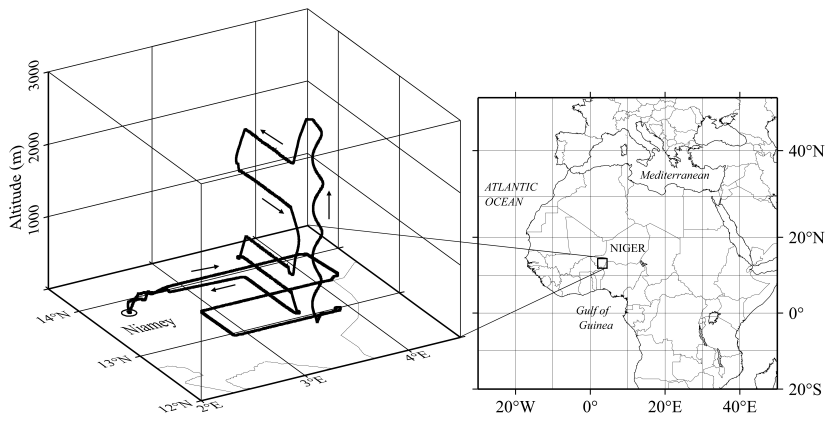

Fig. 1. The geographical location of the measurement area and a representative flight pattern of stacked horizontal legs of the ATR42 aircraft (from 5 August 2006).

\section{Sampling and analysis}

Particles entering the two probes were directly collected using two-stage cascade impactors. The impactor used in this study is basically identical to that described in Matsuki et al. (2005a, b). The aerodynamic diameter at which particles are collected with $50 \%$ collection efficiency was at $1.6 \mu \mathrm{m}$ and $0.2 \mu \mathrm{m}$, respectively, at the first and second stage of the impactor with a volume flow rate of approximately 1.0 L $\mathrm{min}^{-1}$ (1013 hPa, $\left.293 \mathrm{~K}\right)$. Practically, supermicron particles are selectively found on the first stage, since the critical Stokes number (corresponds to 50\% collection efficiency) would approximately be the same at an aerodynamic diameter of $1.6 \mu \mathrm{m}$ and Stokes diameter of $1.0 \mu \mathrm{m}$ with a larger particle density found in the actual atmosphere (e.g. about $2.7 \mathrm{~g} \mathrm{~cm}^{-3}$ for dust particles). Meanwhile, particles collected on the second stage are representative of the accumulation mode $(0.1<D p<1 \mu \mathrm{m})$ particles.

One representative flight track of the ATR-42 aircraft is shown in Fig. 1. In every flight, 5 or 6 samples were collected corresponding to the number of stacked horizontal flight legs made during the stepwise descent from $5 \mathrm{~km}$ down to $0.4 \mathrm{~km}$ (above mean sea level), which included 1 or 2 samples via $\mathrm{CVI}$ in the presence of stratocumulus clouds. In total 7 flights of that type were conducted in the vicinity of Niamey on 4, 5, 6, 7, 13, 14 and 17 August 2006. Each sampling lasted 15-20 min depending on the duration of the respective flight leg. Collodion film on an electron microscopic grid made of nickel (MAXTAFORM Reference Finder Grids, H7, 400 mesh) was chosen as the sampling substrate. After the flight, the particle-laden grids were kept sealed under dry condition $(\mathrm{RH}<40 \%)$ until they were analyzed in the laboratory on individual particle basis.

The current study is based mainly on the morphological and chemical analysis of individual supermicron particles found on the first stage of the impactor. The samples were imaged firstly under a digitized transmission electron microscope (TEM, Hitachi H-7650) to obtain high resolution images of the particles. About 10 randomly chosen fields of view per sample were imaged at a constant magnification $(3000 \times)$ at $120 \mathrm{kV}$ acceleration voltage. Then, by following the references marked on the finder grids, the same fields were located again under a scanning electron microscope (SEM, JEOL, JSM-5910LV) coupled to an energy dispersive X-ray spectroscopy (EDX, Princeton Gamma-Tech, Prism2000), in order to obtain the elemental composition of the individual supermicron particles. The X-ray spectra were collected at $20 \mathrm{kV}$ acceleration voltage and $15 \mathrm{~mm}$ working distance. The relative atomic fractions (\%) of the detected elements were quantified by the manufacturer's software in standard-less mode. Due to the limitation of the method regarding the quantification of lighter elements contained in a single particle, $\mathrm{C}, \mathrm{N}$, and $\mathrm{O}$ were excluded from the quantitative analysis (i.e. a pure $\mathrm{CaSO}_{4}$ particle would give atomic fractions of $50 \% \mathrm{Ca}$ and $50 \% \mathrm{~S}$ ).

On average, 50 particles on each grid were analyzed on manual basis. Some samples had insufficient particle loadings mainly due to the short collection time and low atmospheric concentrations. Samples failing to have more than 30 analyzed particles (6 out of 37) were excluded from this work due to the lack of representativeness.

Due to the technical difficulty related to the detection of lighter elements such as Nitrogen by the EDX analysis, half of the sample substrates were prepared using the abovementioned grids with additional nitron $\left(\mathrm{C}_{20} \mathrm{H}_{16} \mathrm{~N}_{4}\right)$ coating. The nitron reagent film is a reactive film for identifying particulate nitrate (Isawa and Ono, 1979). After sampling, nitron film is treated in the octanol vapor in order to facilitate precipitation of needle like crystals specifically around the particles containing nitrate $\left(\mathrm{NO}_{3}^{-}\right)$.

Particles identified as mineral dust were further segregated into 5 mineral groups depending on the relative atomic fractions found in every particle. For example, "Quartz" $\left(\mathrm{SiO}_{2}\right)$ was the group of particles having more than $85 \%$ of $\mathrm{Si}$. The largest number of the dust particles was assigned to "Aluminosilicate I" such as Feldspar, Mica and various clay minerals. They are more difficult to distinguish solely from the elemental composition, however, particles resembling Amphibole, or particles with exceptionally high Fe content, as well as Ti containing particles were extracted to form another group "Aluminosilicate II". Particles enriched in $\mathrm{Ca}$ were termed "Calcite" $\left(\mathrm{CaCO}_{3}\right)$ and those enriched in $\mathrm{Ca}$ and $\mathrm{Mg}$ "Dolomite" $\left(\mathrm{CaMg}\left(\mathrm{CO}_{3}\right)_{2}\right)$. The classification criteria used for the grouping of mineral dust particles are summarized in Table 1. 
Table 1. Mineral classification of individual dust particles based on the elemental composition (atomic fraction, \%).

\begin{tabular}{|c|c|c|c|}
\hline \multicolumn{2}{|r|}{ Groups } & Classification criteria & Mineralogy deduced \\
\hline & & & from elemental composition \\
\hline 1 & Quartz & $\mathrm{Si}>85 \%$ & Quartz \\
\hline 2 & Aluminosilicate I & not in other classes & $\begin{array}{l}\text { Clay (kaolinite, smectite, illite), } \\
\text { mica (muscovite, biotite), feldspar }\end{array}$ \\
\hline 3 & Aluminosilicate II & $\begin{array}{l}\mathrm{Ti}>3 \% \text { or } \mathrm{Fe} / \mathrm{Si}>1 \\
\text { or }(\mathrm{Mg}+\mathrm{Fe}) / \mathrm{Al}>1 \\
\text { and } \mathrm{K}<3 \% \text { and } \mathrm{Mg} / \mathrm{Si}<1\end{array}$ & Amphibole, hematite, anatase \\
\hline 4 & Calcite & $\mathrm{Si} / \mathrm{Ca}<1$ and $\mathrm{Mg} / \mathrm{Ca}<0.5$ & Calcite, gypsum \\
\hline 5 & Dolomite & $\mathrm{Si} / \mathrm{Ca}<1$ and $\mathrm{Mg} / \mathrm{Ca}>0.5$ & Dolomite \\
\hline
\end{tabular}

\section{Results and discussion}

\subsection{Major particle types and their origin}

\subsubsection{Morphology and composition}

A representative electron micrograph of cloud residual particles collected via CVI is shown in Fig. 2. Presence of a silicate dust particle can be identified by the typical irregular shape and the dominant $\mathrm{X}$-ray peaks corresponding to $\mathrm{Al}$ and Si (Fig. 2a). More than $90 \%$ of such coarse particles exceeding $1 \mu \mathrm{m}$ in diameter composed of the following 3 major types, namely, silicate dust particle (Fig. 2a), sea salt (Fig. 2b), and spherical particles enriched in $\mathrm{Ca}$ (Fig. 2c). These three types were dominating regardless of whether they were cloud residual (in-cloud) or clear-sky particles. Minor types included particles rich in $\mathrm{Cl}$ and $\mathrm{K}$ that are linked to biomass burning (Mouri et al., 1996; Li et al., 2003). Few particles were found enriched in $P$ and $K$, which may be attributed to biogenic origin (Artaxo et al., 2002).

Silicate particles contained elements such as $\mathrm{Na}, \mathrm{Mg}, \mathrm{Al}$, $\mathrm{Si}, \mathrm{K}, \mathrm{Ca}, \mathrm{Ti}$ and $\mathrm{Fe}$, in various combinations, indicating that they are composed of (or mixtures of) quartz, feldspar, mica, amphibole and different clay minerals. Most of the sea salt particles collected in the vicinity of Niamey had lower $\mathrm{Cl} / \mathrm{Na}$ atomic fractions relative to sea water, which is an indication of aging due to the $\mathrm{Cl}$ liberation during transport (Hara et al., 2002).

A majority of the Ca-rich particles often included fractions of $\mathrm{Al}$ and $\mathrm{Si}$ which implies their crustal origin. However, their spherical shape does not match with the generally accepted concept of the "irregular" dust particles. About $90 \%$ of the total Ca dominant particles found on the inert collodion film showed a spherical shape (Fig. 2c), and they were not as electron dense as the irregular silicate particle (Fig. 2a).

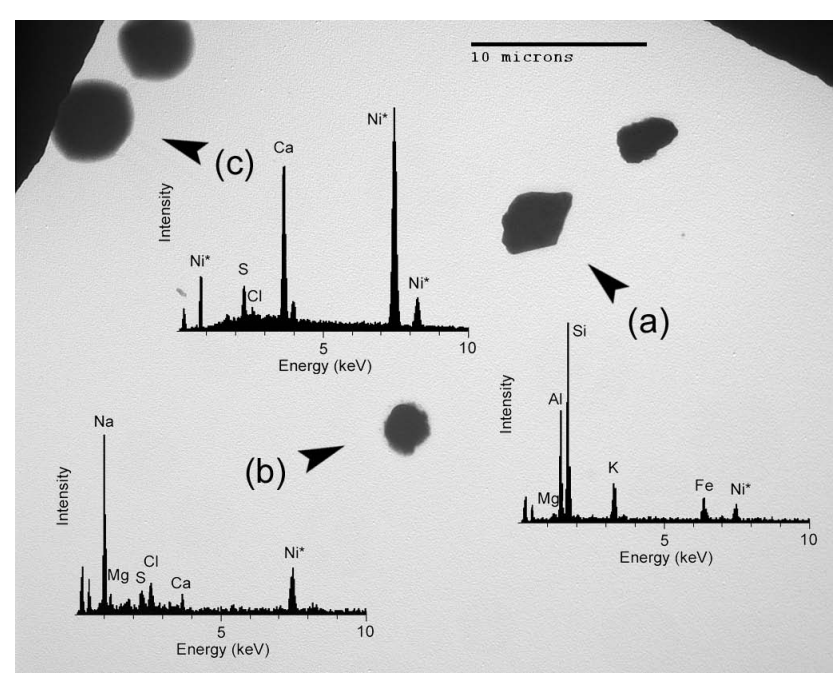

Fig. 2. Representative electron micrograph and X-ray spectra of super-micron particles collected via CVI inside a cloud layer on 14th August 2008. *Peak of Ni results from the metal film support.

With respect to the Ca-rich particles collected on the reactive nitron reagent film, At least $60 \%$ up to $90 \%$ of the Carich particles on the reactive nitron reagent film contained $\mathrm{NO}_{3}^{-}$. It becomes evident that mineral dust particles enriched in carbonate minerals such as calcite $\left(\mathrm{CaCO}_{3}\right)$ and dolomite $\left(\mathrm{MgCa}\left(\mathrm{CO}_{3}\right)_{2}\right)$ react with $\mathrm{HNO}_{3}$ gas to form extremely hygroscopic $\mathrm{Ca}\left(\mathrm{NO}_{3}\right)_{2}$ or $\mathrm{Mg}\left(\mathrm{NO}_{3}\right)_{2}$ which are suggested to readily deliquesce under subsaturated atmospheric conditions (Krueger et al., 2003, 2004; Laskin et al., 2005; Matsuki et al., 2005b). Although carbonate minerals are reported to comprise significant fraction of the atmospheric irregular dust particles in many parts of the globe (Ganor and Mamane, 1982; Okada and Kai, 1995; Krueger et al., 

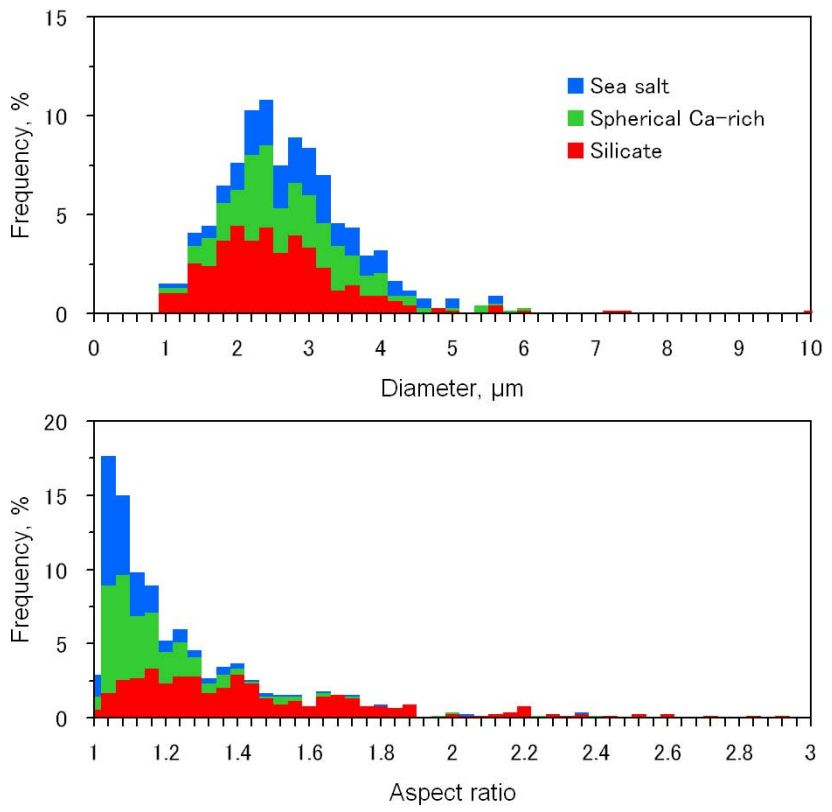

Fig. 3. Frequency distributions of size (upper panel) and aspect ratio (lower panel) for the different particle classes. The result is based on analyzing about 800 particles collected on inert collodion film either as clear-sky aerosol (via CAI) or cloud residues (via CVI).

2004; Kandler et al., 2007), irregularly shaped Ca-rich particles were hardly found in this study. Therefore, the spherical Ca-rich particles containing $\mathrm{NO}_{3}^{-}$can be considered as the atmospherically processed carbonate-rich dust particles (i.e. mainly calcite and dolomite).

The spherical shape of the processed Ca-rich particles most likely results from the expected amorphous metastable state of $\mathrm{Ca}\left(\mathrm{NO}_{3}\right)_{2}$ that contains residual water persisting even in high vacuum (Tang and Fung, 1997). From the bulk volume of the semi transparent particle, $\mathrm{Ca}, \mathrm{S}$ and/or $\mathrm{Cl}$ are commonly found for elements $\mathrm{Z}>\mathrm{Na}$ (Fig. 2c). The X-ray signals of $\mathrm{Al}$ and $\mathrm{Si}$ in the $\mathrm{Ca}$-rich particles were relatively strong in the bright spots (dark spots under TEM) often found in the particle centers. These spots are most likely the aluminosilicate residues suspended in the amorphous $\mathrm{Ca}\left(\mathrm{NO}_{3}\right)_{2}$.

Though it will be discussed more in detail in a companion paper, dust particles found in the accumulation mode $(0.1<D p<1 \mu \mathrm{m})$ were almost entirely hexagonally shaped particles enriched in $\mathrm{Al}$ and $\mathrm{Si}$ (most likely to be kaolinite). They accounted for roughly $20 \%$ of the analyzed submicron particles. Majority of the fine particles were classified as biomass burning particles $(50 \%)$ due to their characteristic potassium-salt inclusions. The remaining fraction was made up by sulfate particles (30\%). Only few sea salt particles were found. In general, the submicron particles in higher altitudes tended to show signs of aging with increasing contribution from sulfates.

\subsubsection{Particle size and aspect ratio}

We have extracted size and aspect ratio of all analyzed particles on the inert collodion film (those collected on the nitron reagent film were excluded since reaction product can interfere with the morphological analysis) and the result is shown in Fig. 3. The diameters of the analyzed particles were determined by the square root of the equivalent projected area on the TEM images. Most of the particles were found within the $1<D p<4 \mu \mathrm{m}$ range, which is fairly consistent with the expected lower and upper cut-size limits of the impactor stage and the aircraft inlet. Although some losses of even larger particles were expected, there was no remarkable difference in the size distribution of particles collected via CAI and CVI in this size range.

In terms of shape, an aspect ratio was determined for each particle by the ratio between the major and minor axis of the best fit ellipse on the projected particle area. Frequency distribution of aspect ratio for the major particle types is shown in Fig. 3. As expected, we found variety of aspect ratios especially with the irregular silicate dust particles. The median aspect ratio was found around 1.4 and more than half of the silicate particles showed ratios $>1.3$. With respect to sea salt and spherical Ca-rich particles assumed to be carbonate, these particles were often found not in irregular crystalline forms but rather as deliquesced droplets, thus showed more round shape with low aspect ratios. We have to note however, that the 2-dimentional scale of such liquid or ductile particles may not always correspond to that in the actual atmosphere, since the particles can be flattened upon impaction.

\subsubsection{Origin of major particles}

If we compare the relative abundance amongst the mentioned particle types, there was a tendency that sea salt particles predominate in the lowest $1.5 \mathrm{~km}$ (Fig. 4). In the contrary, dust particles (Sum of silicate and Ca-rich particles: Quartz + Aluminosilicate + Calcite + Dolomite) predominated over sea salt in higher altitudes $(>1.5 \mathrm{~km})$. Although found in very few numbers, sea salt particles internally mixed with silicates were typically found in the cloud residual samples (6 out of 7 samples).

The 5-day backward trajectory analysis clearly depicts the complete turnover of the wind regime across this altitude (Fig. 5). The trajectory calculation was made using METEX developed by NIES-CGER (Zeng et al., 2003). Figure 5 shows that the air mass arriving at lowest $1.5 \mathrm{~km}$ came from the gulf of Guinea due to the prominent south-westerly monsoon flux typical of the season, thus carried more sea salt particles.

Dust particles were predominant in higher altitudes (1.5$4 \mathrm{~km}$ ), where the layer of warm and dry Saharan air layer (SAL, or so-called Harmattan) was persistently approaching from east to north-east most likely influenced by the presence of the African Easterly Jet (AEJ). At even higher altitudes 

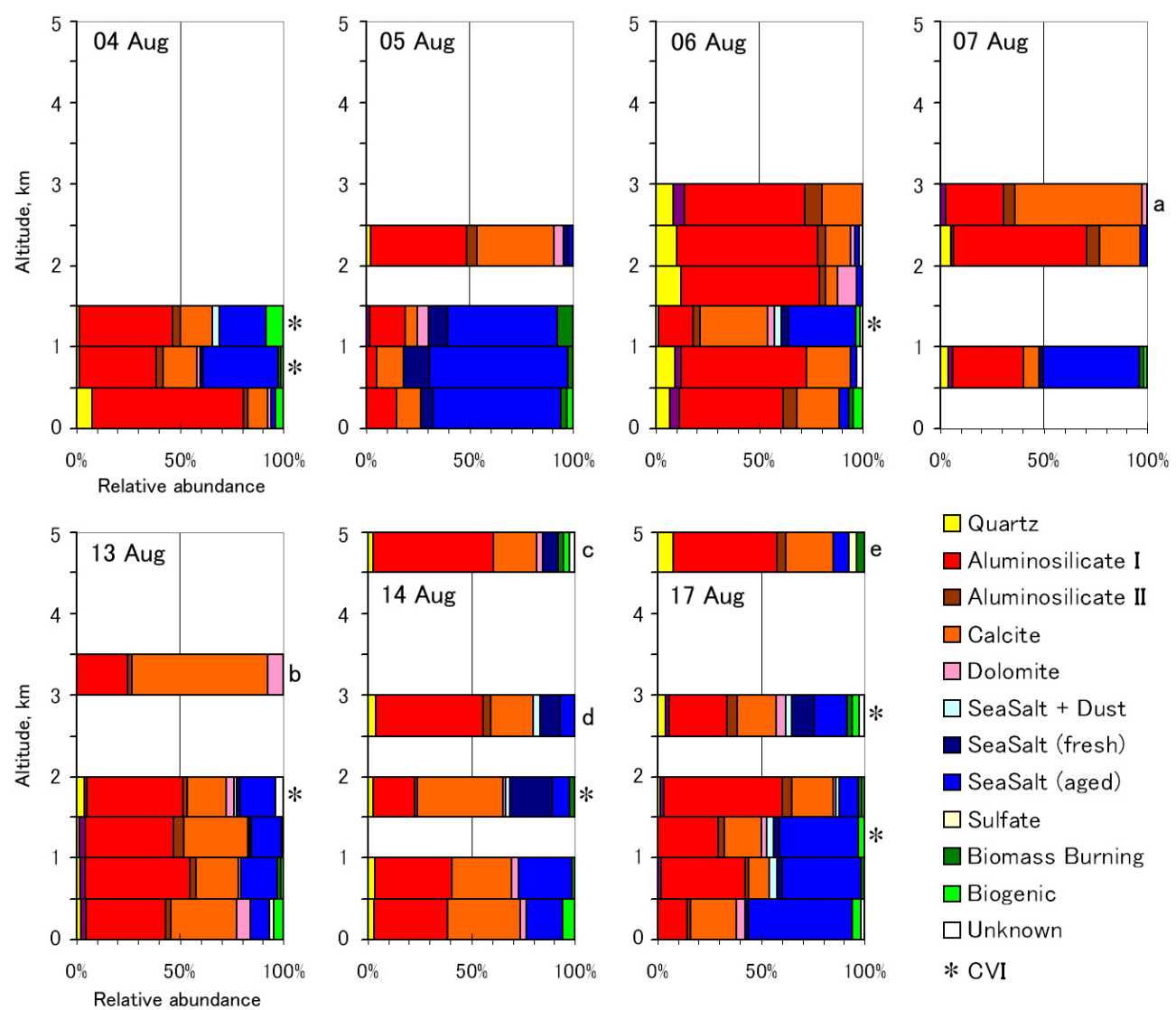

Fig. 4. Various types of super-micron particles $(D p>1 \mu \mathrm{m})$ and their relative abundance found in the clear-sky and in-cloud samples. Each sample represents a $0.5 \mathrm{~km}$ vertical interval in which it was sampled. In-cloud (CVI) samples are indicated by the asterisks $(*)$. Characters (a) to (e) relate selection of samples to the peculiar air-mass trajectories shown subsequently in Fig. 5.

(4-5 km), air mass often arrived after making a descending anticyclonic curve around the Saharan high (Cook, 1999).

There are number of reports indicating that the surface soils in the Sahelian region to be depleted in calcite (Claquin et al., 1999; Kandler et al., 2007; Castillo et al., 2008; Formenti et al., 2008). Instead, these studies attribute Northern Sahara to be the major source when dust particles are particularly enriched in $\mathrm{Ca}$. Thus, fairly large number fraction of Ca-rich particles found in this study rather associates Northern Sahara to be the likely source than the Sahelian region, however, it was not quite as straightforward since none of the 5-day backward trajectories traced anywhere near the ground surface over Northern Sahara (Fig. 5).

Kandler et al. (2007) showed that the significant increase in the relative mass fraction of Ca-containing particles in $2.5<D p<10 \mu \mathrm{m}$ to be associated with air mass previously passing below $1000 \mathrm{~m}$ a.s.l. over the North-Western Africa. At the same time however, the mineralogy within $1<D p<2.5 \mu \mathrm{m}$ range did not seem to be affected as much by the north to south gradient of the Ca content in African soils. In addition, the mass fractions of carbonates and other $\mathrm{Ca}$ rich particles were larger in $1<D p<2.5 \mu \mathrm{m}$ range (10-20\%) than in $2.5<D p<10 \mu \mathrm{m}$ range ( $<5 \%$ before 19 July 2005 in their report), which leaves the possibility that there may be constant Ca source other than the North-Western Sahara especially for the smaller size range. The mineralogy they have presented for the smaller size range $(1<D p<2.5 \mu \mathrm{m})$ is perhaps more relevant for the particles collected in our study $(1<D p<4 \mu \mathrm{m})$. Nevertheless, it is difficult to explicitly locate the source of the collected dust particles, and the question remains whether the regions to the south of Sahara can really be the source of such small calcite particles. This supposed size-fractionated mineralogy of the Sahara-Sahel regions is an interesting aspect that we should take into account in the future course of the study.

Interestingly, dust particles were more abundant than sea salt particles even in all the cloud residual samples for the above mentioned 7 local flights in the vicinity of Niamey (Niger). With respect to the cloud residual sampling by CVI however, one has to evaluate the degree of possible contamination by the large and heavy interstitial particles. Due to its large size and density, dust particles have the potential to aerodynamically mimic the cloud droplets. 


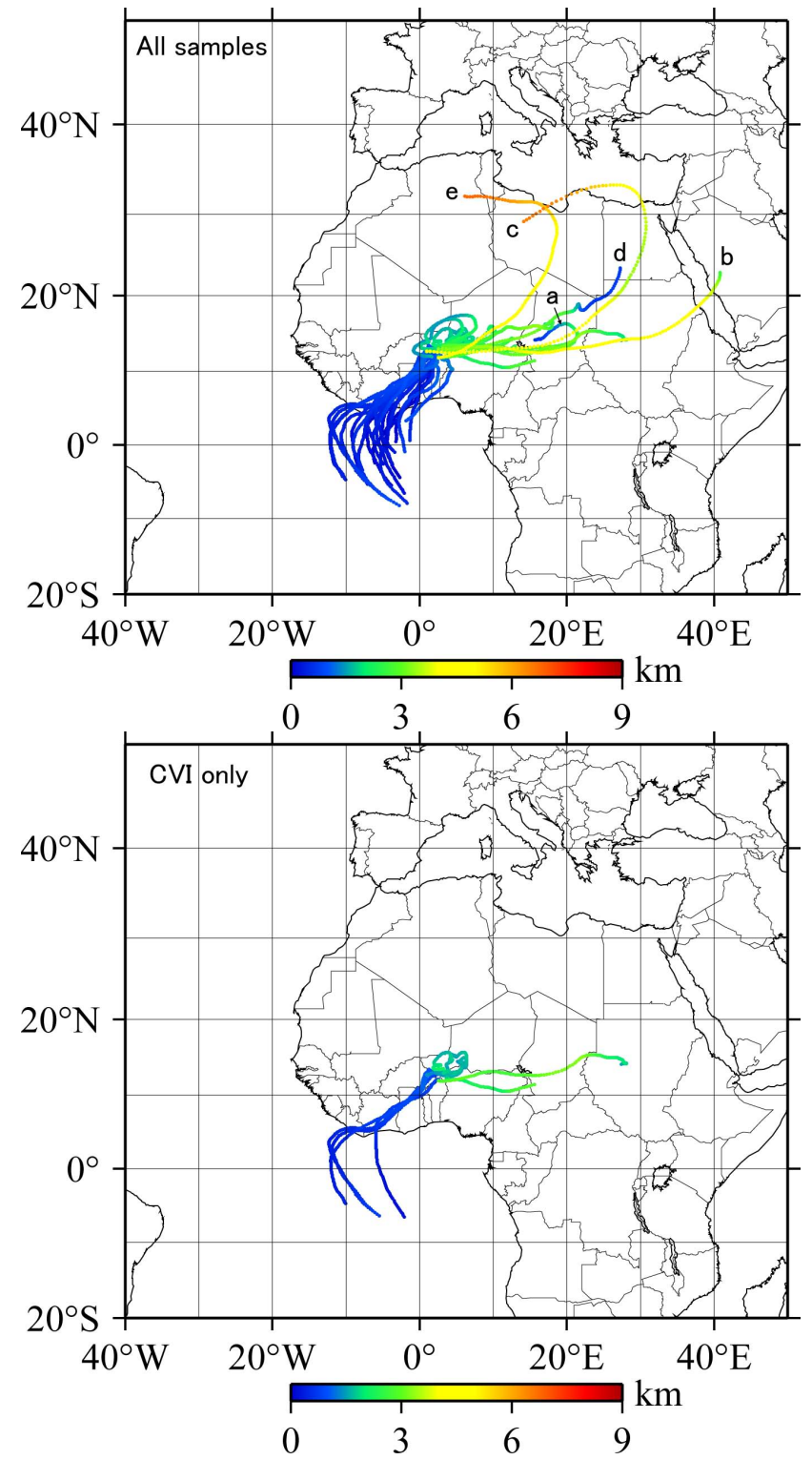

Fig. 5. The 5-day air-mass backward trajectories arriving at the point of collection for all the samples (upper graph), and extraction of in-cloud (CVI) samples only (lower graph). Several peculiar trajectories are labeled by the characters (a) to (e).

In reality, clouds are spatially inhomogeneous and the observed stratocumulus clouds were quite often patchy. Consequently, the number concentration of cloud residual particles measured by the OPC during a given CVI operation fluctuated remarkably as the aircraft repeatedly entered and left the cloud patches. Ideally, the OPC count should drop to 0 when the aircraft leaves the cloud. Although significant counts appeared only when the aircraft was inside the cloud, few counts continued to appear even outside of the cloud patches. The sum of particles $D p>1 \mu \mathrm{m}$ counted in the gaps of the cloud was up to $10 \%$ of the total counts obtained during a CVI sample leg with a typical in-cloud operation time of 50\% (0\% in clear-sky and $100 \%$ in a homogeneous cloud). Even if we assume that a similar number of interstitial particles was collected by the CVI inside the clouds (meaning that largest particles would not at all have been activated), the sum of collected interstitial particles within clouds plus total particles outside cloud could have been up to $20 \%$ on the CVI sample leg. Therefore, most of the coarse particles (at least 80\%) collected via CVI can be considered as those found in the actual cloud droplets.

Since the stratocumulus clouds often appeared close to the boundary of the two wind regimes at about $1.5 \mathrm{~km}$, the air mass trajectories arriving at the level of CVI operations showed the mixed characteristics of both the monsoon flux and the SAL (Fig. 5).

In order to make a strict comparison between the mineral composition found in and outside of clouds, several clear-sky sample with peculiar trajectories which differ significantly from those of the CVI samples are extracted and marked by alphabets (Figs. 4, 5). For example, trajectories (b), (c) and (e) suggest that the collected dust particles arrived after long-range transport from even distant sources. Trajectory (b) suggest transport of air mass from the Arabian Peninsula. (c) and (e) on the other hand, air mass arrived from exceptionally high altitudes after making a descending anticyclonic curve around the Saharan region. The rapid ascending motion in trajectories (a) and (d) suggest presence of exceptionally strong convective system (e.g. MCS). Trajectory accuracy can be deteriorated in the vicinity of such fronts or cyclones (Doty and Perkey, 1993; Zeng et al., 2003). Therefore, dust particles found within samples (a) to (e) may have different sources, or previously undergone intense atmospheric processing (longer lifetime, cloud processing in highly convective clouds, etc.).

\subsection{Heterogeneous reaction on dust particles}

Based on the X-ray spectra, 1495 of the total supermicron particles (1883) were identified as mineral dust, including the Ca-rich particles assumed to be modified carbonates (i.e. Calcite and Dolomite). The spectra (including the samples with nitron reagent film) further showed that the significant fraction of the dust particles contained $\mathrm{S}, \mathrm{Cl}$, and $\mathrm{NO}_{3}^{-}$.

Figure 6 compares the detection frequencies of $\mathrm{S}, \mathrm{Cl}$, and $\mathrm{NO}_{3}^{-}$among the dust particles of different mineralogy. Clearly, the detection frequencies of $\mathrm{S}, \mathrm{Cl}$, and $\mathrm{NO}_{3}^{-}$were unevenly distributed in the 5 mineral groups. Such mineralogical dependence should not be seen if these components became internally mixed with the dust particles as a result of coagulation (Matsuki et al., 2005a).

For the case of $\mathrm{S}$, sulfate can be found as primary dust component in the form of gypsum. It must be noted that, a gypsum particle $(\mathrm{S} / \mathrm{Ca}$ ratio $=1.0)$ would as well be classified as Calcite in the current classification. However, not 

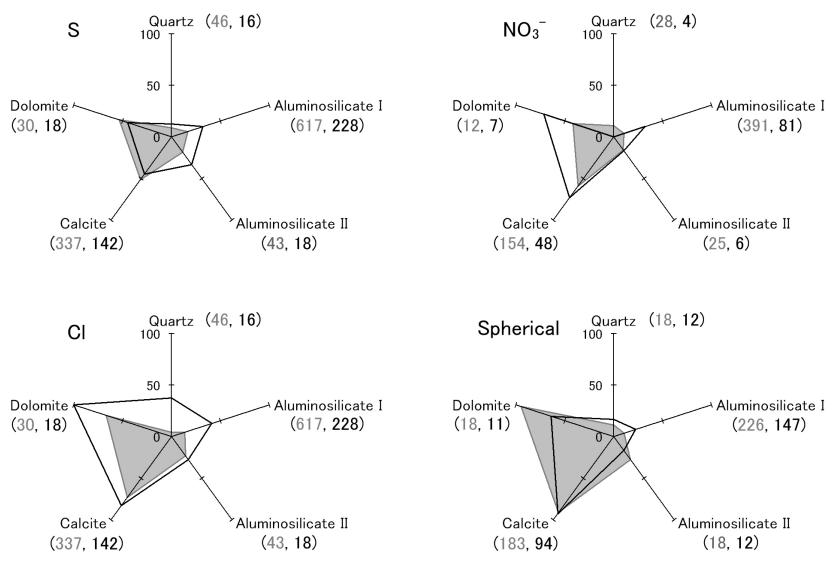

Fig. 6. Detection frequencies of $\mathrm{S}$ and $\mathrm{Cl}$ elements (by SEM-EDX) as well as $\mathrm{NO}_{3}^{-}$ion (using nitron reagent film) among the individual mineral dust particles of different mineralogy. Fractions of particles resembling spherical particles (Fig. 2c) are also compared. The Fe rich and Ti containing fraction (Aluminosilicate II) was distinguished from the major aluminosilicate particles (Aluminosilicate I) for comparison. The detection frequencies are compared between the clear-sky (gray area) and in-cloud (solid black line) samples. The absolute numbers of total investigated particles from the clearsky (gray) and in-cloud (black) samples are indicated in the parenthesis.

many pure gypsum particles were found in this study. Half of the Ca-rich particles classified as Calcite did not even contain $\mathrm{S}$, while only less than $10 \%$ reached $\mathrm{S} / \mathrm{Ca}$ ratio $>0.4$. If any, gypsum was only partially present as internal mixtures with the Ca-rich particles. Thus, it can be assumed that the good part of the Ca-rich particles was initially made of calcium carbonate. Further, there were many silicate particles containing excess $\mathrm{S} / \mathrm{Ca}$ ratio $(>1.0)$ as well as those containing $\mathrm{S}$ without $\mathrm{Ca}$, which could not be explained solely by the inclusion of gypsum.

The overall picture in Fig. 6 did not change even if we excluded all dust particles containing $\mathrm{Na}$, demonstrating the minor effect of the possible mixing of sea salt and dust particles. Thus, Fig. 6 demonstrates the selective formation of sulfate, nitrate, chloride upon the heterogeneous uptake (and subsequent oxidation) of reactive gases (e.g. $\mathrm{SO}_{2}, \mathrm{HNO}_{3}$, $\mathrm{NO}_{\mathrm{x}}, \mathrm{HCl}, \mathrm{O}_{3}$ ) on the different mineral surfaces (Goodman et al., 2001; Hanish and Crowley, 2001; Underwood et al., 2001; Usher et al., 2002, 2003; Ooki and Uematsu, 2005; Vlasenko et al., 2006).

It was also found that, $\mathrm{S}, \mathrm{Cl}$, and $\mathrm{NO}_{3}^{-}$had a common distribution pattern in the 5 mineral groups (Fig. 6). Quartz particles were the least reactive of all groups $(<10 \%)$. Aluminosilicate II group was separated from the majority of the clay minerals (Aluminosilicate I), in order to isolate the possible uptake enhancement by the catalytic behavior of transition metal oxides such as Fe and Ti (Brandt and Vaneldik, 1995; Ivanov et al., 1998). However, the detection frequen- cies for Aluminosilicate II were found to be similar in extent, or only slightly higher (16-23\%) than Aluminosilicate I (10$17 \%$ ). In contrast, Ca-rich particles classified as Calcite and Dolomite showed exceptionally higher detection frequencies in all the three components (42-73\%). It is well known that these two major carbonates are particularly susceptible to acids. Figure 6 demonstrates that this alkaline nature of the carbonates is also reflected in the high uptake coefficient of the acidic gases.

\subsection{Cloud processing of dust particles}

One of the main interests of the current study is to demonstrate how such processing of dust particles would further proceed in the actual cloud droplets (i.e. cloud processing). Figure 6 also compares the detection frequencies of $\mathrm{S}, \mathrm{Cl}$, and $\mathrm{NO}_{3}^{-}$between the dust particles collected via CVI (incloud) and CAI (clear-sky). If we focus firstly on the major Aluminosilicate I group represented by the largest number of analyzed particles (845 particles out of total 1495), it is evident that the detection frequencies of all the three components showed remarkable increase of about two to threefold in-cloud (32-41\%) as compared to clear-sky conditions $(10-17 \%)$. This is most likely reflecting the accelerated uptake and oxidation of the acidic gases in the aqueous phase, although incorporation of interstitial aerosols into the cloud droplets may also play a role in mixing these components with dust particles. For the Calcite group represented by the second largest number of particles (479 particles), the increase in the detection frequency of $\mathrm{S}$ was not as evident as for $\mathrm{Cl}$ and $\mathrm{NO}_{3}^{-}$. It was suggested that the rate of $\mathrm{S}$ accumulation onto $\mathrm{Ca}$-rich particles was not particularly higher in-cloud as compared to clear-sky conditions, at least under the situations encountered during the current campaign.

It was surprising to find almost all Ca-rich particles in the modified unusual spherical form (Fig. 6) despite considering the proximity to the dust source region and the remoteness from heavily inhabited cities or major industries. Unfortunately, gaseous data is not available on the same aircraft. At least, the observed deficit in the $\mathrm{Cl} / \mathrm{Na}$ ratio is a sign that gaseous $\mathrm{HCl}$ had been released from the sea salt particles. Also, local biogenic emission of $\mathrm{NO}_{\mathrm{x}}$ from wetted soils in the Sahel has been spotted by the British BAe-146 aircraft deployed during the same campaign (Stewart et al., 2008). $\mathrm{O}_{3}$ formation was also observed in relation to this $\mathrm{NO}_{\mathrm{x}}$ emission from soils.

It is generally expected that chloride and nitrate are more prone to concentrate on supermicron dust particles, unless particles had previously taken up exceeding amount of nonvolatile sulfate (Sullivan et al., 2007). The hygroscopicity of the resulting $\mathrm{Ca}$ salts may depend highly on the reacting acidic gas. If gypsum $\left(\mathrm{CaSO}_{4} \cdot 2 \mathrm{H}_{2} \mathrm{O}\right)$ forms as a result of $\mathrm{SO}_{2}$ uptake and subsequent oxidation on a calcite particle, the change in the hygroscopicity may not be as dramatic as in the case of $\mathrm{Ca}\left(\mathrm{NO}_{3}\right)_{2}$ formation, since gypsum is only 
slightly soluble (Kelly et al., 2007). The possibility remains that $\mathrm{CaCl}_{2}$ also turns calcite particles very hygroscopic (Tobo et al., 2009). It is also interesting to find the formation of water along the $\mathrm{CO}_{2}$ emission during the effervescence as shown in Eq. (1).

$$
\begin{aligned}
& \mathrm{CaCO}_{3}(s)+2 \mathrm{HNO}_{3}(g)= \\
& \mathrm{Ca}\left(\mathrm{NO}_{3}\right)_{2}(a q)+\mathrm{H}_{2} \mathrm{O}(a q)+\mathrm{CO}_{2}(g)
\end{aligned}
$$

Hence, the acquisition of hygroscopicity and water molecule is a combined process. Further uptake of the acidic gas and water vapor in the atmosphere can lead to the eventual dissolution of an entire carbonate particle, which explains the presence of the observed Ca-rich spherical particles with high $\mathrm{NO}_{3}^{-}$detection frequency (Fig. 6).

Although we cannot fully exclude the possibility that the particles had previously experienced clouds, it is interesting to find that almost all Ca-rich particles were in their characteristic spherical form even in clear-sky conditions. This is in accordance with the laboratory experiments and modeling studies which suggests that the active uptake of $\mathrm{HNO}_{3}$ gas on the carbonate particles and the consecutive deliquescence readily takes place even under relatively dry conditions in the actual atmosphere (Tang and Fung, 1997; Krueger et al., 2003, 2004; Kelly and Wexler, 2005; Laskin et al., 2005; Gibson et al., 2006a, b).

In order to take a closer look on the effect of supposed adsorption of water molecules on the silicate surface and the eventual immersion into the droplet, the detection frequencies of $\mathrm{S}$ and $\mathrm{Cl}$ on all silicate particles (Quartz + Aluminosilicate I \& II) were plotted as a function of mean relative humidity at which the particles were collected (Fig. 7). As for the CVI samples, the mean relative humidity was obtained simply by averaging over the entire CVI operation regardless of how patchy the cloud layer was, hence CVI samples collected in more broken clouds tended to give smaller relative humidity $<100 \%$.

An interesting relation was found in Fig. 7, such that the number of silicate particles containing detectable amount of $\mathrm{S}$ and $\mathrm{Cl}$ increases with increasing relative humidity, and that the higher numbers were often found especially among the samples collected in clouds. Similar acceleration of $\mathrm{SO}_{2}$ uptake as a function of relative humidity has been reported previously (Huray et al., 1978; Dlugi et al., 1981; Matsuki et al., 2005a), however, Fig. 7 steps further to isolate the actual cloud processing from the clear-sky processing. Since CCN particles may undergo on average ten evaporation/condensation cycles before they finally precipitate (Pruppacher and Jaenicke, 1995), this is a clear demonstration that the dust particle composition can be significantly altered depending on the cloud presence along their long-range transport.

Another interesting feature is that, the samples related to the peculiar air-mass trajectories (trajectories (a) to (e) in

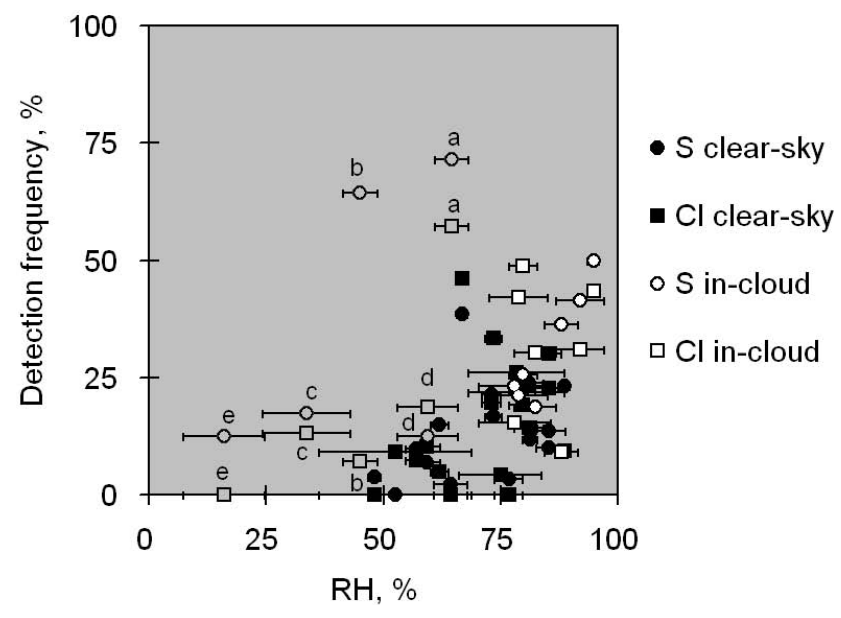

Fig. 7. Detection frequencies of $\mathrm{S}$ and $\mathrm{Cl}$ elements in the silicate particles (Quartz, Aluminosilicate I+ II) plotted against the relative humidity at which the sample was collected. Error bar shows a standard deviation $(\sigma)$. Samples collected in-cloud and clear-sky conditions are compared. Characters (a) to (e) show detection frequencies for the samples associated with the peculiar air-mass trajectories identified in Fig. 5.

Fig. 5) stray significantly away from the majority of the plots in Fig. 7. The trajectories suggested that dust particles in these samples may either have experienced aging through very long-range transport, or encountered highly convective situations and thus, significant cloud processing. This is well reflected in the detection frequencies of $\mathrm{S}$ and $\mathrm{Cl}$ found in silicate particles such that these samples do not generally fit with the increasing trend seen in Fig. 7. In the contrary, dust particles in the majority of the samples were still relatively fresh and had little $\mathrm{S}$ or $\mathrm{Cl}$ content especially under low relative humidity conditions.

\subsection{The influence of composition on the $\mathrm{CCN}$ activity of mineral dust}

As mentioned earlier, the majority of the coarse particles $(D p>1 \mu \mathrm{m})$ collected via CVI in this study were dust particles. The probability of the interstitial dust particles contaminating the CVI samples being small indicates that most of the coarse particles collected by the CVI were extracted from the actual cloud droplets.

Scavenging of interstitial aerosol by cloud droplets due to particle diffusion is highly efficient for removing nanometer sized particles which takes place within a matter of few minutes, but takes days for supermicron particles (Seinfeld and Pandis, 1998). Dust particles can be incorporated into cloud droplets also through coagulation. In order to test the probability of interstitial dust particles $(D p=2 \mu \mathrm{m}$, particle density $\left.2.7 \mathrm{~g} \mathrm{~cm}^{-1}\right)$ colliding with the cloud droplets $(D p=10 \mu \mathrm{m}$, droplet concentration $200 \mathrm{~cm}^{-3}$ ), coagulation coefficients K $\left(\mathrm{m}^{3} \mathrm{~s}^{-1}\right)$ in the turbulent flow regime were calculated after 
Saffman and Turner (1956). The turbulent energy dissipation rates of $10^{-4}$ to $10^{-1} \mathrm{~m}^{2} \mathrm{~s}^{-3}$ were assumed which are typically found in stratocumulus and non-precipitating cumulus clouds (Kitchen and Caughey, 1981; Caughey et al., 1982; Smith and Jonas, 1995). The life time of a dust particle in the cloud estimated based on the coagulation coefficient is about $7.5 \mathrm{~h}$ even under a rather turbulent condition with turbulent energy dissipation rate of $0.1 \mathrm{~m}^{2} \mathrm{~s}^{-3}$. This may be too long as compared to the average residence times of air parcels in clouds, which is said to be of the order of an hour. Scarcity of internally mixed silicate and sea salt particles may also indicate slow scavenging of the coarse particles. Thus, dust particles extracted from the cloud drops can be considered as those previously activated as $\mathrm{CCN}$.

The remaining question is then whether or not all dust particles had the similar potential to act as CCN. Kelly et al. (2007) predicted that for dust particles between roughly 0.6 and $2 \mu \mathrm{m}$, the presence of slightly soluble components can induce activation of dust particles that would not activate if entirely insoluble (supersaturations $0.1-0.2 \%$ ). Laboratory study of Gibson et al. (2006) showed that $\mathrm{Ca}\left(\mathrm{NO}_{3}\right)_{2}$ particles have the similar $\mathrm{CCN}$ activity as $\left(\mathrm{NH}_{4}\right)_{2} \mathrm{SO}_{4}$ which activate at much lower supersaturations than $\mathrm{CaCO}_{3}$ particles, which implies that modified Ca-rich particles found in this study would show greater $\mathrm{CCN}$ activity than the rest of the dust particles. At the same time, soluble materials found on many silicate particles may as well have enhanced their CCN activity.

Interestingly, we found two cloud-residual samples (out of seven samples) in which we counted more Ca-rich particles than the silicates. This is not the case in the average clearsky samples as well as in other regions where silicate particles usually predominate (Trochkine et al., 2003; Okada and Kai, 1995; Kandler et al., 2007). This might be a sign that more hygroscopic Ca-rich particles were selectively acting as $\mathrm{CCN}$ in these particular two cases. Unfortunately however, given the limited number of the cloud residual samples and analyzed particles in the current study, and without knowing the exact dust fraction which remained interstitial, this issue cannot be addressed in further detail.

In any case, current result clearly demonstrated that both Ca-rich and silicate dust particles can be frequently found in the actual cloud droplets, and it is highly probable that the preceding acquisition of soluble materials through atmospheric processing facilitated their cloud activation.

\section{Conclusions}

In this study, individual particle analysis was applied on the actual cloud residues collected in-situ by the airborne CVI. The morphology and mixing states of the cloud residues were directly compared with those of the clear-sky aerosols collected immediately adjacent to the cloud layer. This ap- proach was proved effective in characterizing the $\mathrm{CCN}$ relevant aerosols as well as the influence of cloud processing.

Although the $\mathrm{CCN}$ activity of dust particles has been significantly overlooked due to the generally supposed insolubility of silicates, many coarse dust particles were found as cloud residues over the Sahelian region during the summer monsoon period. There was a sharp contrast between the dust particles found in and out of the cloud in terms of the detection frequencies of associated secondary acidic species (sulfate, chloride, nitrate). It is a clear demonstration that the uptake coefficients of acidic gases on dust particles are dependent firstly on the relative humidity, and then they are drastically enhanced upon incorporation into cloud droplets. As a consequence, the employment of relative humidity dependent uptake coefficients is strongly recommended in the global aerosol models for the improved representation of the mineral dust. Since CCN particles may undergo on average ten evaporation/condensation cycles before they finally precipitate in droplets (Pruppacher and Jaenicke, 1995), the amount of and duration in clouds along the dust transport pathways can have significant impact both on the dust composition itself as well as on the atmospheric chemistry (Dentener et al., 1996; Bauer and Koch, 2005).

Surprisingly large portion of $\mathrm{Ca}$-rich particles assumed to be carbonate were found in a characteristic spherical shape most probably following the uptake of $\mathrm{HNO}_{3}$ gas. Since almost all the Ca-rich particles were forming spherical shapes (even outside of the clouds and away from any significant anthropogenic emission source), it is concluded that such dramatic phase transition readily takes place in the actual atmosphere.

Due to their alkaline nature, Ca-rich particles assumed to be carbonate were found particularly reactive at presence of acidic gases, as compared to silicate particles. Although silicate and Ca-rich particles are supposed to share the same emission sources and thus are grouped together as "mineral dust", their behavior is completely different given their reactivity and the ability to readily deliquesce in the atmosphere. This mineralogical diversity of dust particles certainly deserves much more attention from the atmospheric modeling community since the optical properties as well as the interaction with clouds/water cycles is far from being uniform for different kind of dust particles, which in addition are modified due to atmospheric processing.

Both silicate and $\mathrm{Ca}$-rich particles were found dominant among the supermicron cloud residues, and they were supposed to be those previously activated as $\mathrm{CCN}$ rather than incorporated into cloud drops through coagulation. Due to their large sizes, supermicron particles are often believed to act as CCN regardless of their composition. This assumption may generally apply for conditions with relatively high supersaturations $(>0.2 \%)$. However, ambient supersaturations are said to be typically around $0.1 \%$. In particular, the maximum supersaturation expected in stratocumulus clouds such as the ones we encountered with updraft velocities $0-1 \mathrm{~ms}^{-1}$ 
can be as low as $0.05 \%$ (Seinfeld and Pandis, 1998). Under certain conditions, the influence of particle chemistry can not be neglected especially for insoluble particles such as mineral dust, where addition of soluble material can drastically reduce critical supersaturation (Dusek et al. 2006). Therefore, it is highly probable that the formation of soluble materials through atmospheric processing enhanced the cloud nucleating abilities of both the Ca-rich and silicate particles.

Finally, this study focused mainly on the inorganic chemistry due mainly by the limitation of the methodology employed (elemental analysis). Dust processing by organic materials may be overlooked which also has a potential to affect the particle's cloud nucleating abilities via dust-biomass burning interactions. Their presence might bias the results of the inorganic interpretation and this issue remains as a future consideration.

Acknowledgements. Based on a French initiative, AMMA was built by an international scientific group and is currently funded by a large number of agencies, especially from France, UK, US and Africa. It has been the beneficiary of a major financial contribution from the European Community's Sixth Framework Research Programme. Detailed information on scientific coordination and funding is available on the AMMA International web site http://www.amma-international.org. This work was funded by the French API-AMMA, CNES, INSU, and the Japan Society for the Promotion of Science. We thank all the staffs and pilots of SAFIRE (Service des Avions Français Instruments pour la Recherche en Environnement, Toulouse) for their help and support. We also thank J.-M. Henot. and B. Devouard of LMV (Laboratoire Magmas et Volcans, Clermont-Ferrand), C. Drégnaux and C. Szczepaniak of CICS (Centre Imagerie Cellulaire Santé, Clermont-Ferrand), S. Nitsche, D. Chaudanson, O. Grauby, D. Vielzeuf, A. Baronnet, D. Ferry, of CRMCN (Centre de Recherche en Metière Condensée et Nanosciences, Marseille), for their assistance in realizing the single particle analysis.

\section{Edited by: P. Formenti}

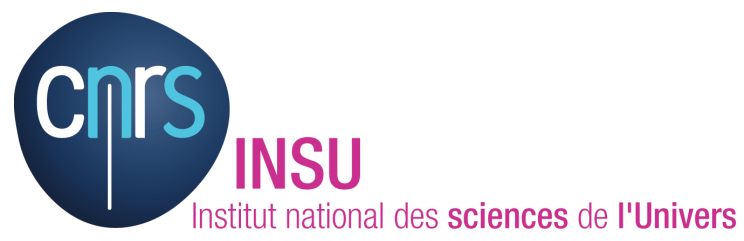

The publication of this article is financed by CNRS-INSU.

\section{References}

Albrecht, B. A.: Aerosols, cloud microphysics, and fractional cloudiness, Science, 245, 1227-1229, 1989.

Archuleta, C. M., DeMott, P. J., and Kreidenweis, S. M.: Ice nucleation by surrogates for atmospheric mineral dust and mineral dust/sulfate particles at cirrus temperatures, Atmos. Chem. Phys., 5, 2617-2634, 2005, http://www.atmos-chem-phys.net/5/2617/2005/.

Artaxo, P., Martins, J. V., Yamasoe, M. A., Procopio, A. S., Pauliquevis, T. M., Andreae, M. O., Guyon, P., Gatti, L.V., and Leal, A. M. C.: Physical and chemical properties of aerosols in the wet and dry seasons in Rondônia, Amazonia, J. Geophys. Res., 107(D20), 8081, doi:10.1029/2001JD000666, 2002.

Bauer, S. E. and Koch, D.: Impact of heterogeneous sulfate formation at mineral dust surfaces on aerosol loads and radiative forcing in the Goddard Institute for Space Studies general circulation model, J. Geophys. Res., 110, D17202, doi:10.1029/2005JD005870, 2005.

Brandt, C. and Vaneldik, R.: Transition-metal-catalyzed oxidation of sulfur(IV) oxides - atmospheric-relevant processes and mechanisms, Chem. Rev., 95(1), 119-190, 1995.

Caughey, S. J., Crease, B. A., and Roach, W. T.: A field study of nocturnal stratocumulus II: Turbulence structure and entrainment, Q. J. Roy. Meteorol. Soc., 108, 125-144, 1982.

Castillo, S., Moreno, T., Querol, X., Alastuey, A., Cuevas, E., Herrmann, L., Mounkaila, M., and Gibbons, W.: Trace element variation in size-fractionated African desert dusts, J. Arid Environ., 72, 1034-1045, 2008.

Claquin, T. and Schulz, M.: Modeling the mineralogy of atmospheric dust sources, J. Geophys. Res., 104(D18), 22243-22256, 1999.

Cook, K. H.: Generation of the African Easterly Jet and its role in determining West African precipitation, J. Clim., 12, 1165-1184, 1999.

DeMott, P. J., Sassen, K., Poellot, M. R., Baumgardner, D., Rogers, D. C., Brooks, S. D., Prenni, A. J., and Kreidenweis, S. M.: African dust aerosols as atmospheric ice nuclei, Geophys. Res. Lett., 30(14), 1732, doi:10.1029/2003GL017410, 2003.

Dentener, F. J., Carmichael, G. R., Zhang, Y., Lelieveld, J., and Crutzen, P. J.: Role of mineral aerosol as a reactive surface in the global troposphere, J. Geophys. Res., 101(D17), 22869-22880, 1996.

Dlugi, R., Jordan, S., and Lindemann, E.: The heterogeneous formation of sulfate aerosols in the atmosphere, J. Aerosol Sci., 12, 185-190, 1981.

Doty, K. G. and Perkey, D. J.: Sensitivity of trajectory calculations to the temporal frequency of wind data, Month. Weather Rev., 121, 387-401, 1993.

Dusek, U., Frank, G. P., Hildebrandt, L., Curtius, J., Schneider, J., Walter, S., Chand, D., Drewnick, F., Hings, S., Jung, D., Borrmann, S., and Andreae, M. O.: Size matters more than chemistry for cloud-nucleating ability of aerosol particles, Science, 312, 1375-1378, 2006.

Feingold, G., Cotton, W. R., Kreidenweis, S. M., and Davis, J. T.: The impact of giant cloud condensation nuclei on drizzle formation in stratocumulus: Implications for cloud radiative properties, J. Atmos. Sci., 56(24), 4100-4117, 1999.

Formenti, P., Elbert, W., Maenhaut, W., Haywood, J., and Andreae, M. O.: Chemical composition of mineral dust aerosol dur- 
ing the Saharan Dust Experiment (SHADE) airborne campaign in the Cape Verde region, September 2000, J. Geophys. Res., 108(D18), 8576, doi:10.1029/2002JD002648, 2003.

Formenti, P., Rajot, J. L., Desboeufs, K., Caquineau, S., Chevaillier, S., Nava, S., Gaudichet, A., Journet, E., Triquet, S., Alfaro, S., Chiari, M., Haywood, J., Coe, H., and Highwood, E.: Regional variability of the composition of mineral dust from western Africa: Results from the AMMA SOP0/DABEX and DODO field campaigns, J. Geophys. Res., 113, D00C13, doi:10.1029/2008JD009903, 2008.

Ganor, E. and Mamane, Y.: Transport of Saharan dust across the eastern Mediterranean, Atmos. Environ., 16, 581-587, 1982.

Gibson, E. R., Hudson, P. K., and Grassian V. H.: Aerosol chemistry and climate: Laboratory studies of the carbonate component of mineral dust and its reaction products Geophys. Res. Lett., 33, L13811, doi:10.1029/2006GL026386, 2006.

Gibson, E. R., Hudson, P. K., and Grassian V. H.: Physicochemical Properties of Nitrate Aerosols: Implications for the Atmosphere, J. Phys. Chem. A, 110, 11785-11799, 2006.

Goodman, A. L., Bernard, E. T., and Grassian, V. H.: Spectroscopic study of nitric acid and water adsorption on oxide particles: Enhanced nitric acid uptake kinetics in the presence of adsorbed water, J. Phys. Chem. A, 105, 6443-6457, 2001.

Hanisch, F. and Crowley, J. N.: Heterogeneous reactivity of gaseous nitric acid on $\mathrm{Al}_{2} \mathrm{O}_{3}, \mathrm{CaCO}_{3}$, and atmospheric dust samples: A Knudsen cell study, J. Phys. Chem. A, 105(13), 3096-3106, 2001.

Hara, K., Osada, K., Nishita, C., Yamagata, S., Yamanouchi, T., Herber, A., Matsunaga, K., Iwasaka, Y., Nagatani, M., and Nakata, H.: Vertical variations of sea-salt modification in the boundary layer of spring Arctic during the ASTAR 2000 campaign, Tellus, 54B, 361-376, 2002.

Haywood, J., Francis, P., Osborne, S., Glew, M., Loeb, N., Highwood, E., Tanré, D., Myhre, G., Formenti, P., and Hirst, E.: Radiative properties and direct radiative effect of Saharan dust measured by the C-130 aircraft during SHADE: I. Solar spectrum, J. Geophys. Res., 108, 8577, doi:10.1029/2002JD002687, 2003.

Heintzenberg, J., Okada, K., and Ström, J.: On the composition of non-volatile material in upper tropospheric aerosols and cirrus crystals, Atmos. Res., 41, 81-88, 1996.

Isawa, Y. and Ono, A.: Nitron thin film method for detection of submicron nitrate particles and its application to atmospheric aerosols, J. Meteorol. Soc. Jpn., 57(6), 599-606, 1979.

Huary, G., Jordan, S., and Hofmann, C.: Experimental investigation of the aerosol-catalyzed oxidation of SO2 under atmospheric conditions, Atmos. Environ., 12, 281-287, 1978.

Isono, K., Komabayashi, M., and Ono, A.: The nature and the origin of ice nuclei in the atmosphere, J. Meteorol. Soc. Jpn., 37, 211233, 1959.

Ivanov, V. P., Kochubey, D. I., Kutzenogii, K. P., and Bufetov, N. S.: Surface composition of atmospheric aerosols, React. Kinet. Catal. Lett., 64, 97-102, 1998.

Kandler, K., Benker, N., Bundke, U., Cuevas, E., Ebert, M., Knippertz, P., Rodriguez, S., Schutz, L., and Weinbruch, S.: Chemical composition and complex refractive index of Saharan Mineral dust at Izana, Tenerife (Spain) derived by electron microscopy, Atmos. Environ., 41, 8058-8074, 2007.

Kelly, J. T. and Wexler, A. S.: Thermodynamics of carbonates and hydrates related to heterogeneous reactions in- volving mineral aerosol. J. Geophys. Res., 110, D11201, doi:10.1029/2004JD005583, 2005.

Kelly, J. T., Chuang, C. C., and Wexler, A. S.: Influence of dust composition on cloud droplet formation, Atmos. Environ., 41, 2904-2916, 2007.

Kitchen, M. and Caughey, S. J.: Tethered-balloon observations of the structure of small cumulus clouds, Q. J. Roy. Meteorol. Soc., 107, 853-874, 1981.

Krueger, B. J., Grassian, V. H., Laskin, A., and Cowin, J. P.: The transformation of solid atmospheric particles into liquid droplets through heterogeneous chemistry: Laboratory insights into the processing of calcium containing mineral dust aerosol in the troposphere, Geophys. Res. Lett., 30(3), 1148, doi:10.1029/2002GL016563, 2003.

Krueger, B. J., Grassian, V. H., Cowin, J. P., and Laskin, A.: Heterogeneous chemistry of individual mineral dust particles from different dust source regions: the importance of particle mineralogy, Atmos. Environ., 38, 6253-6261, 2004.

Krueger, B. J., Grassian, V. H., Cowin, J. P., and Laskin, A.: Erratum to "Heterogeneous chemistry of individual mineral dust particles from different dust source regions: the importance of particle mineralogy", Atmos. Environ., 39, p. 395, 2005.

Laskin, A., Iedema, M. J., Ichkovich, A., Graber, E. R., Taraniuk, I., and Rudich, Y.: Direct observation of completely processed calcium carbonate dust particles, Faraday Discuss., 130, 453468, 2005.

Levin, Z., Ganor, E., and Gladstein, V.: The effects of desert particles coated with sulfate on rain formation in the Eastern Mediterranean, J. Appl. Meteorol., 35, 1511-1523, 1996.

Li, J., Pósfai, M., Hobbs, P. V., and Buseck, P. R.: Individual aerosol particles from biomass burning in southern Africa: 2. Compositions and aging of inorganic particles, J. Geophys. Res., 108(D13), 8484, doi:10.1029/2002JD002319, 2003.

Lohmann, U., Kärcher, B., and Hendricks, J.: Sensitivity studies of cirrus clouds formed by heterogeneous freezing in the ECHAM GCM, J. Geophys. Res., 109(D16), 204, doi:10.1029/2003JD004443, 2004.

Matsuki, A., Iwasaka, Y., Shi, G. Y., Chen, H. B., Osada, K., Zhang, D., Kido, M., Inomata, Y., Kim, Y. S., Trochkine, D., Nishita, C., Yamada, M., Nagatani, T., Nagatani, M., and Nakata, H.: Heterogeneous sulfate formation on dust surface and its dependence on mineralogy: Balloon-borne measurements in the surface atmosphere of Beijing, China, Water Air Soil Poll., 5, 101-132, 2005a.

Matsuki, A., Iwasaka, Y., Shi, G. Y., Zhang, D. Z., Trochkine, D., Yamada, M., Kim, Y. S., Chen, B., Nagatani, T., Miyazawa, T., Nagatani, M., and Nakata, H.: Morphological and chemical modification of mineral dust: Observational insight into the heterogeneous uptake of acidic gases, Geophys. Res. Lett., 32(22), L22806, doi:10.1029/2005GL024176, 2005b.

Mouri, H., Nagao, I., Okada, K., Koga, S., and Tanaka, H.: Elemental composition of individual aerosol particles collected from the coastal marine boundary layer, J. Meteor. Soc. Jpn., 74, 585-591, 1996.

Ogren, J. A., Heintzenberg J., and Charlson R. J.: In-situ sampling of clouds with a droplet to aerosol converter. Geophys. Res. Lett. 12, 121-124, 1985.

Okada, K. and Kai, K.: Features and elemental composition of mineral particles collected in Zhangye, China, J. Meteorol. Soc. Jpn., 
73(5), 947-957, 1995.

Ooki, A. and Uematsu, M.: Chemical interactions between mineral dust particles and acid gases during Asian dust events, J. Geophys. Res., 110, D03201, doi:10.1029/2004JD004737, 2005.

Pruppacher, H. R. and Jaenicke, R.: The processing of water vapor and aerosols by atmospheric clouds, a global estimate, Atmos. Res., 38, 283-295, 1995.

Redelsperger, J. L., Thorncroft, C. D., Diedhiou, A., Lebel, T., Parker, D. J., and Polcher, J.: African Monsoon Multidisciplinary Analysis: An international research project and field campaign, B. Am. Meteorol. Soc., 87(12), 1739-1746, doi:10.1175/BAMS87-12-1739, 2006.

Rosenfeld, D., Rudich, Y., and Lahav, R.: Desert dust suppressing precipitation: A possible desertification feedback loop, Proc. Natl. Acad. Sci. USA, 98(11), 5975-5980. 2001.

Saffman, P. G. and Turner, J. S.: On the collision of drops in turbulent clouds, J. Fluid Mech., 1, 16-30, 1956.

Sassen, K., DeMott, P. J., Prospero, J. M., and Poellot, M. R.: Saharan dust storms and indirect aerosol effects on clouds: CRYSTAL-FACE results, Geophys. Res. Lett., 30, 1633, doi:10.1029/2003GL017371, 2003.

Schwarzenboeck, A. and Heintzenberg, J.: Cut size minimization and cloud element break-up in a ground-based CVI, J. Aerosol Sci., 31, 477-489, 2000.

Schwarzenboeck, A., Heintzenberg, J., and Mertes, M.: Incorporation of aerosol particles between 25 and $850 \mathrm{~nm}$ into cloud elements: measurements with a new complementary sampling system, Atmos. Res., 52, 241-260, 2000.

Seinfeld, J. H., and Pandis, S. N.: Atmospheric Chemistry and Physics: From Air Pollution to Climate Change, Wiley, New York, 1998.

Smith, S. A. and Jonas, P. R.: Observations of the turbulent fluxes in fields of cumulus clouds, Q. J. Roy. Meteorol. Soc., 121, 11851208, 1995 .

Sokolik, I., Winker, D. M., Bergametti, G., Gillette, D. A., Carmichael, G., Kaufman, Y., Gomes, L., Schuetz, L., and Penner, J. E.: Introduction to special section: outstanding problems in quantifying the radiative impacts of mineral dust, J. Geophys. Res. 106, 18015-18028, 2001.

Stewart, D. J., Taylor, C. M., Reeves, C. E., and McQuaid, J. B.: Biogenic nitrogen oxide emissions from soils: impact on $\mathrm{NO}_{\mathrm{x}}$ and ozone over west Africa during AMMA (African Monsoon Multidisciplinary Analysis): observational study, Atmos. Chem. Phys., 8, 2285-2297, 2008, http://www.atmos-chem-phys.net/8/2285/2008/.

Sullivan, R. C., Guazzotti, S. A., Sodeman, D. A., and Prather, K. A.: Direct observations of the atmospheric processing of Asian mineral dust, Atmos. Chem. Phys., 7, 1213-1226, 2007a, http://www.atmos-chem-phys.net/7/1213/2007/.

Sullivan, R. C., Guazzotti, S. A., Sodeman, D. A., Tang, Y., Carmichael, G. R., and Prather K. A.: Mineral dust is a sink for chlorine in the marine boundary layer, Atmos. Environ., 41, 7166-7179, 2007b.
Tanaka, T. Y. and Chiba, M.: Global simulation of dust aerosol with a chemical transport model MASINGAR, J. Meteorol. Soc. Jpn., 83A, 255-278, 2005.

Tang, I. N. and Fung, K. H.: Hydration and Raman scattering studies of levitated microparticles: $\mathrm{Ba}\left(\mathrm{NO}_{3}\right)_{2}, \mathrm{Sr}\left(\mathrm{NO}_{3}\right)_{2}$, and $\mathrm{Ca}\left(\mathrm{NO}_{3}\right)_{2}$, J. Chem. Phys., 106(5), 1653-1660, 1997.

Tobo, Y., Zhang, D., Nakata, N., Yamada, M., Ogata, H., Hara, K., and Iwasaka, Y.: Hygroscopic mineral dust particles as influenced by chlorine chemistry in the marine atmosphere, Geophys. Res. Lett., 36(5), L05817, 2009.

Trochkine, D., Iwasaka, Y., Matsuki, A., Yamada, M., Kim, Y S., Nagatani, T., Zhang, D., Shi, G. Y., and Shen, Z.: Mineral aerosol particles collected in Dunhuang, China, and their comparison with chemically modified particles collected over Japan, J. Geophys. Res., 108(D23), 8642, doi:10.1029/2002JD003268, 2003.

Twohy, C. H., and Poellot, M. R.: Chemical characteristics of ice residual nuclei in anvil cirrus clouds: evidence for homogeneous and heterogeneous ice formation, Atmos. Chem. Phys., 5, 22892297, 2005, http://www.atmos-chem-phys.net/5/2289/2005/.

Twomey, S.: Pollution and the planetary albedo, Atmos. Environ., 8, 1251-1256, 1974.

Underwood, G. M., Song, C. H., Phadnis, M., Carmichael, G. R., and Grassian, V. H.: Heterogeneous reactions of $\mathrm{NO}_{2}$ and $\mathrm{HNO}_{3}$ on oxides and mineral dust: A combined laboratory and modeling study, J. Geophys. Res., 106(D16), 18055-18066, 2001.

Usher, C. R., Al-Hosney, H., Carlos-Cueller, S., and Grassian, V. H.: A laboratory study of the heterogeneous uptake and oxidation of sulfur dioxide on mineral dust particles, J. Geophys. Res., 107(D23), 4713, doi:10.1029/2003JD004309, 2002.

Usher, C. R., Michel, A. E., and Grassian, V. H.: Reactions on mineral dust, Chem. Rev., 103(12), 4883-4939, 2003.

Vlasenko, A., Sjogren, S.,Weingartner, E., Stemmler, K., Gaggeler, H. W., and Ammann, M.: Effect of humidity on nitric acid uptake to mineral dust aerosol particles, Atmos. Chem. Phys., 6, $2147-$ 2160, 2006, http://www.atmos-chem-phys.net/6/2147/2006/.

$\mathrm{Wu}$, P.-M. and Okada, K.: Nature of coarse nitrate particles in the atmosphere-A single particle approach, Atmos. Environ., 28, 2053-2060, 1994.

Zeng, J., Tohjima, Y., Fujinuma, Y., Mukai, H., and Katsumoto, M.: A study of trajectory quality using methane measurements from Hateruma Island, Atmos. Environ., 37, 1911-1919, 2003.

Zhang, D. and Iwasaka, Y.: Chlorine deposition on dust particles in marine atmosphere, Geophys. Res. Lett., 28, 3613-3616, 2001.

Zhu, X., Prospero, J. M., Millero, F. J., Savoie, D. L., and Brass, G. W.: The solubility of ferric ion in marine mineral aerosol solutions at ambient relative humidities, Mar. Chem., 38(1-2), 91-107, 1992. 